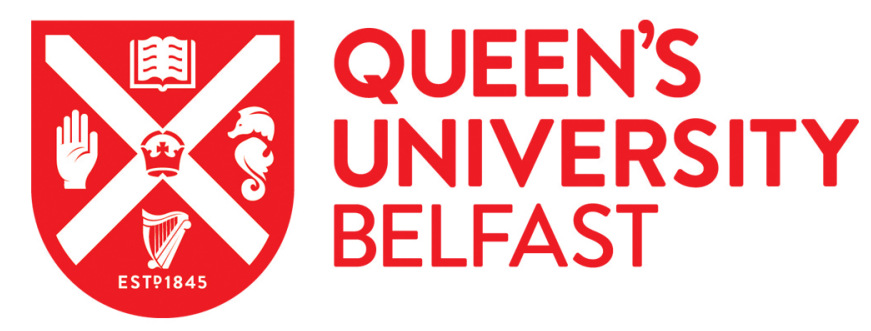

\title{
Lead-bismuth eutectic corrosion behaviors of ferritic/martensitic steels in low oxygen concentration environment
}

Liu, J., Shi, Q., Luan, H., Yan, W., Sha, W., Wang, W., Shan, Y., \& Yang, K. (2015). Lead-bismuth eutectic corrosion behaviors of ferritic/martensitic steels in low oxygen concentration environment. Oxidation of Metals, 84(3), 383-395. https://doi.org/10.1007/s11085-015-9560-5

Published in:

Oxidation of Metals

Document Version:

Peer reviewed version

Queen's University Belfast - Research Portal:

Link to publication record in Queen's University Belfast Research Portal

\section{General rights}

Copyright for the publications made accessible via the Queen's University Belfast Research Portal is retained by the author(s) and / or other copyright owners and it is a condition of accessing these publications that users recognise and abide by the legal requirements associated with these rights.

Take down policy

The Research Portal is Queen's institutional repository that provides access to Queen's research output. Every effort has been made to ensure that content in the Research Portal does not infringe any person's rights, or applicable UK laws. If you discover content in the Research Portal that you believe breaches copyright or violates any law, please contact openaccess@qub.ac.uk. 
First author: Jian Liu

Email addresses: jliu12b@imr.ac.cn

Corresponding author: Ke Yang

Email addresses: kyang@imr.ac.cn

Corresponding author addresses: Institute of Metal Research, Chinese Academy of Sciences, 72 Wenhua Road,

Shenyang, China 110016 Tel.:+86 2423971628 Fax: +86 2423971628

\title{
Lead-bismuth eutectic corrosion behaviors of ferritic/martensitic steels in low oxygen concentration environment
}

Jian Liu ${ }^{\mathrm{a}, \mathrm{b}}$, Quanqiang Shi ${ }^{\mathrm{a}, \mathrm{b}}$, He Luan ${ }^{\mathrm{a}, \mathrm{b}}$, Wei Yan ${ }^{\mathrm{a}}$, Wei Sha ${ }^{\mathrm{c}}$, Wei Wang ${ }^{\mathrm{a}}$, Yiyin Shan ${ }^{\mathrm{a}}$, Ke Yang ${ }^{\mathrm{a},{ }^{*}}$

${ }^{a}$ Institute of Metal Research, Chinese Academy of Sciences, Shenyang 110016, China

${ }^{\mathrm{b}}$ University of Chinese Academy of Sciences, Beijing 100049, China

${ }^{\mathrm{c}}$ School of Planning, Architecture \& Civil Engineering, Queen's University Belfast, Belfast BT9 $5 \mathrm{AG}, \mathrm{UK}$

${ }^{*}$ Corresponding author. Tel.: +86 24 23971628; fax: +86 2423971628

E-mail address: kyang@imr.ac.cn (Ke Yang)

\begin{abstract}
In order to investigate the compatibility of the candidate structural materials with liquid metals, two kinds of ferritic/martensitic steels were chosen to contact with lead-bismuth eutectic in sealed quartz glass tubes. The corrosion process lasted for $500 \mathrm{~h}$ and $3000 \mathrm{~h}$. Results showed that the oxidation layer and carbide dissolution layer on the two steels grew with contact time under oxygen unsaturated condition. Short-term corrosion behavior of SIMP showed better lead-bismuth eutectic corrosion resistance than T91 at $873 \mathrm{~K}$.
\end{abstract}

Key words: electron microscopy; light microscopy; steel; oxidation; LBE

\section{Introduction}

The current worldwide interests of using lead and its alloys (particularly lead-bismuth eutectic, or LBE) in nuclear applications are very strong [1]. They are considered as the coolant and/or spallation neutron targets in the accelerator driven subcritical (ADS) system, US DOE Advanced Accelerator Applications (AAA) Program and fast breeder reactor (FBR) [1-3]. The candidate structural materials for subcritical transmutation blanket, such as SS316L, SS304, Eurofer97 and T91, however, all face the problem of compatibility with LBE $[4,5]$.

The compatibility tests have been carried out for nuclear reactors of Russia submarine before 
[5]. The results showed that there was a competition between oxidation and dissolution in the corrosion process of Fe-Cr steel [6]. Controlling oxygen concentration in LBE can form a self-healing oxidation layer on the steel surface. The continuous and stable oxide layer can ease the corrosion and dissolution attack from LBE [7]. So, the technologies of monitoring and controlling the oxygen concentration in LBE have become critical issues $[1,7]$. The oxygen potential in LBE must be controlled carefully within the range between $\mathrm{PbO}$ formation and $\mathrm{Fe}_{3} \mathrm{O}_{4}$ formation [7]. If the oxygen potential is too high $\mathrm{PbO}$ particles can precipitate and plug the loop pipes [7]. If the oxygen concentration in LBE is too low to form continuous protective oxidation layer, the dissolution of loop component can cause the contamination of coolant. There is no stable oxidation layer to hinder the component dissolution from the steel in the liquid metal.

At present a method of controlling gas atmosphere is the bubbled mixture of hydrogen and steam. The concentration of oxygen in LBE is controlled by changing the injecting ratio of $\mathrm{H}_{2} / \mathrm{H}_{2} \mathrm{O}$ in the gas atmosphere above the liquid metal, which is monitored by a zirconia-yttria sensor. In some experiments the oxygen concentration in LBE ranged from $10^{-3} \mathrm{wt} \%$ to $10^{-9} \mathrm{wt} \%$ [3-7]. It was found [3-6] that the oxygen concentration LBE has great influence on the growth of oxidation layer. We are not able to give order of magnitude or find the parabolic constants for different oxygen concentration at one constant temperature. Oxygen solubility in $\mathrm{Pb}$ and $\mathrm{Bi}$ varies with temperature. The concentration of oxygen in LBE is very low at low temperature range. The existing LBE corrosion set-ups usually used mixed gas to control the oxygen concentration in LBE. The oxygen concentration depends on the ratio of $\mathrm{H}_{2} / \mathrm{H}_{2} \mathrm{O}$ or $\mathrm{H}_{2} / \mathrm{Ar}$ in gas. The thickness of SIMP oxidation layer in oxygen-saturated LBE at $873 \mathrm{~K}$ was about $40 \mu \mathrm{m}$. More details can be found in Ref. [14].

The objective of present work is to compare corrosion behavior of SIMP and T91 that has been thoroughly studied. The structural material was immersed in LBE in a low oxygen concentration environment, not higher than $5.1 \times 10^{-7} \mathrm{wt} \%$. The oxygen was consumed and a compact oxidation layer was formed protecting the steel matrix from further corrosion. To eliminate the corrosion and dissolution of the test device component, corrosion tests were carried out in sealed quartz glass tubes.

\section{Experiments}

Two steels were used for the static LBE corrosion studies. One was a commercial F/M steel 
T91 widely used in power plants. The other one was a new F/M steel developed by Institute of Metal Research and Institute of Modern Physics, Chinese Academy of Sciences, named SIMP steel. The chemical compositions of the experimental steels are shown in Table 1.

The T91 samples were cut from tubes produced by Sumitomo Metal Industries, Ltd, Japan. The outer diameter of the T91 tubes was $64 \mathrm{~mm}$ and the inner diameter was $46 \mathrm{~mm}$. The T91 steel was in the as-received state that was austenitized at $1323 \mathrm{~K}$ for $20 \mathrm{~min}$, followed by air cooling, and tempered at $1053 \mathrm{~K}$ for $60 \mathrm{~min}$. The standard state of SIMP steel is a tempered martensite microstructure obtained after a normalization treatment, austenitization at $1323 \mathrm{~K}$ for $0.5 \mathrm{~h}$, followed by tempering at $1033 \mathrm{~K}$ for $1.5 \mathrm{~h}$.

The samples for LBE corrosion test were cut into $10 \times 10 \times 5 \mathrm{~mm}$ by electrical discharge machining (EDM), ground with abrasive papers up to 2000\# and polished with flannelette for 15 min before corrosion. The lead-bismuth eutectic pieces were cut by electrical discharge machining and ground to remove the oxide. The samples and lead-bismuth eutectic pieces for test were sealed in quartz glass tube and kept at $873 \mathrm{~K}$. The volume of liquid LBE in quartz tube was $20.34 \mathrm{~cm}^{3}$. The surface area of samples was smaller than $3 \mathrm{~cm}^{2}$. The ratio of surface area of samples over volume of LBE in the test facility was about $3 \mathrm{~cm}^{2} / 20.34 \mathrm{~cm}^{3}$. A quartz glass bar was also sealed in the quartz glass tube to make sure of the samples inserting into the LBE. The times of immersion were $500 \mathrm{~h}$ and $3000 \mathrm{~h}$. The atmosphere above LBE in quartz glass tube was Ar gas with pressure of about $0.02 \mathrm{MPa}$. The purity of the Ar gas was $99.9 \%$. The oxygen concentration in LBE was not higher than $5.1 \times 10^{-7} \mathrm{wt} \%$. The quartz glass tube is shown in Fig.1.

The volume ratio of the LBE over the Ar gas was 1:1, as shown in Fig.1. The pressure of Ar was about $0.02 \times 10^{6} \mathrm{~Pa}$. From PV $=\mathrm{nRT}$, where $\mathrm{R}=8.314 \mathrm{~J} / \mathrm{mol} \cdot \mathrm{K}$ and $\mathrm{T}=293 \mathrm{~K}$, we can obtain $\mathrm{n}=8.21 \mathrm{~V}$ mol. The purity of Ar was $99.9 \%$. Assuming that the impurity was the air, the oxygen in Ar was calculated to be $0.1 \% \times 21 \% \times 32 \mathrm{~g} / \mathrm{mol}=0.00672 \mathrm{~g} / \mathrm{mol}$. The density of LBE is $1.0708 \times 10^{7}$ $\mathrm{g} / \mathrm{m}^{3}$, leading to a maximum oxygen concentration in LBE of $(8.21 \mathrm{~V}) \mathrm{mol} \times 0.00672 \mathrm{~g} / \mathrm{mol} /$ $\left(1.0708 \times 10^{7} \mathrm{~V}\right) \mathrm{g}=5.15 \times 10^{-7} \mathrm{wt} \%$. It is impossible for the oxygen in the Ar gas to dissolve completely in LBE, so the above was the maximum. The oxygen content in LBE at room temperature is smaller than $10^{-8} \mathrm{wt} \%$.

After the experiment, the quartz glass tubes were broken and the samples were extracted from the melt. The residual LBE on the sample surfaces was removed by hot oil at $473 \mathrm{~K}$, and 
then the samples were inlaid by epoxy resin to protect the original oxidation layer. In order to reveal the microstructure of the corroded layer and the matrix, cross sections of some samples were etched by Vilella's reagent $(1 \mathrm{~g}$ of picric acid, $5 \mathrm{ml}$ hydrochloric acid and $100 \mathrm{ml}$ ethyl alcohol). Then examples wrapped by epoxy resin were ground and polished for analyses of cross sections on optical microscopy (OM), scanning electron microscopy (SEM), SEM-energy dispersive spectrometer (EDS) and electron probe microanalyzer (EPMA). The type of SEM pictures, secondary electron (SE) or backscattered electron (BSE), are indicated within the micrographs in the figures. The oxidation layer was composed of outer oxidation layer and inner oxidation layer, not including the carbide dissolution layer beneath the inner oxidation layer.

The liquid lead-bismuth alloy used in the test had an eutectic composition, $55.5 \mathrm{wt} \% \mathrm{Bi}$ and $44.5 \mathrm{wt} \% \mathrm{~Pb}$. The liquid lead-bismuth melt contained a few ppm of impurities, $\mathrm{Mg}<1 ; \mathrm{Al}<1$; $\mathrm{Si}<10 ; \mathrm{Cr}<1 ; \mathrm{Fe}<5 ; \mathrm{Ni}<1 ; \mathrm{Cu}<1 ; \mathrm{Zn}<1 ; \mathrm{As}<1 ; \mathrm{Sb}<1 ; \mathrm{Ag}<5 ; \mathrm{Cd}<1 ; \mathrm{Sn}<3$, all in ppm.

\section{Results and discussion}

\subsection{Original microstructures}

The microstructures of two F/M steels after heat treatment are shown in Fig.2. The original microstructures are fully tempered martensite. The sizes of primary austenite grains are about 9 $\mu \mathrm{m}$ in T91 steel and $20 \mu \mathrm{m}$ in SIMP steel. The sizes of martensitic laths and sub-grains in SIMP are larger than those in T91. The carbides distribute on the grain boundaries and martensite laths boundaries with high density. Because of higher carbon content, the amount of carbides in SIMP is greater than T91.

\subsection{Surface of specimens}

After LBE corrosion for $500 \mathrm{~h}$ and $3000 \mathrm{~h}$, the surfaces of samples were not attached with the LBE greatly, which shows the bad wettability between steels and LBE. The oxidation layer presented the characteristics of corrosion, as shown in Fig.3. The SEM energy spectrum analyses of Table 2 showed that the oxidation layers of the two steels were both enriched of silicon, oxygen and chromium. It should be noted that the surface morphologies of oxide layers of the two steels are shown in Fig.3. Fig.3-(a) (b) and (c) are T91 surface morphologies, and Fig.3-(d) and (e) are SIMP surface morphologies. They are not cross section of oxide layer but surface morphologies. The oxygen and $\mathrm{Cr}$ contents were higher in Points 1 and 2 in Table 2 than in matrix, and no LBE was detected. So, they both can be considered as oxide layer. Points 1-3 all represent oxide layer. 
Point 1 in Fig.3-(a) has less $\mathrm{O}$ than Point 2 and less Cr than Point 2 and Point 3, but it has higher $\mathrm{O}$ and $\mathrm{Cr}$ than the matrix of steel. So, it is enriched $\mathrm{O}$ and $\mathrm{Cr}$. Some past corrosion tests in LBE of low oxygen content showed that the most outward oxidation layer was magnetite. $\mathrm{Cr}$ in magnetite is lower than $\mathrm{Fe} . \mathrm{Cr}$ and $\mathrm{Mn}$ replace $\mathrm{Fe}$ in spinel lattice. Point 2 showed higher $\mathrm{Cr}$ and $\mathrm{Mn}$ than Point 1 , so it is also possible that Point 1 corresponds to magnetite and Point 2 spinel. Following this assumption, Point 3 showed the spinel layer composition of SIMP. The contents of oxygen and $\mathrm{Si}$ are high. $\mathrm{Cr}$ replaced $\mathrm{Fe}$ and was enriched in oxide layer. Point 2 showed spinel in T91 and Point 1 showed magnetite composition in T91. Spinel $\left(\mathrm{Fe}\left(\mathrm{Fe}_{\mathrm{x}} \mathrm{Cr}_{1-\mathrm{x}}\right)_{2} \mathrm{O}_{4}, 34.9 \% \mathrm{O}\right)$ has more $\mathrm{Cr}$ and $\mathrm{O}$ than magnetite $\left(\mathrm{Fe}_{3} \mathrm{O}_{4}, 27.5 \% \mathrm{O}\right)$. Point 2 has more $\mathrm{Cr}$ and less $\mathrm{Fe}$ than $\mathrm{T} 91$ matrix. The $\mathrm{Cr}$ content in SIMP is higher than T91, as given in Table 1.

Point 2 represents oxide layer because much higher oxygen and the alloying elements, than the normal steel, can be found in Point 2. The outer magnetite layer shelled off partly. The metal atoms migrated to oxide layer and can form many kinds of oxides, such as $\mathrm{SiO}_{2}, \mathrm{MnO}$ and spinel. The migration of atoms resulted in cavities. Some cavities can be found in Fig.4-(c). The Ni in T91 made it more susceptible to dissolution corrosion. So, Point 2 in Fig.3-(a) seems to show a hollowed out morphology. $\mathrm{Cr}$ and Si contents are higher in SIMP than in T91. SIMP can form more compact oxidation layer, with less dissolution corrosion occurring, as shown by comparing Fig.4-(c) and (d).

The oxidation layers on the surfaces showed different characters after the steels were immersed in LBE. The oxidation layer formed on T91 surface is compact. There are some white oxide particles distributing on the surface. The results of surface elemental analysis of T91 and SIMP are shown in Fig.5 and Table 3. Elemental analysis showed that $\mathrm{Pb}$ and $\mathrm{Bi}$ were enriched in the oxide particles. The morphology of the peeled-off area in the oxidation layer is shown in Fig.3. There are compact corrosion layer on the surface and oxide particles in the peeled-off area in the oxidation layer. The elemental concentrations of surfaces of samples in the peeled-off area in the oxidation layer are shown in Table 2. The analysis results show that the corrosion products are diverse. The dominated oxides are Fe-Cr spinel. There are several alloy elements in steels. The metal atoms can migrate to oxide layer and form several kinds of oxides, such as $\mathrm{SiO}_{2}, \mathrm{MnO}_{2}$ and spinel. The internal oxide layer is spinel. $\mathrm{Cr}$, $\mathrm{Si}$ and Fe should be oxidized firstly. The $\mathrm{Si}$ content is low, and the main oxides are $\mathrm{Cr}_{2} \mathrm{O}_{3}$. Cr replaecd Fe in spinel $\mathrm{Fe}\left(\mathrm{Fe}_{\mathrm{x}} \mathrm{Cr}_{1-\mathrm{x}}\right)_{2} \mathrm{O}_{4}$, not in magnetite. So, 
Cr was enriched in spinel layer, as shown in the composition of Point 2. There are also some Cr-Mn oxides and silicon dioxides. The Cr, Mn and Si contents are high in Point 2 (Table 2), compared to matrix (Table 1). It should be noted that the elemental analyses on the surface cannot show the composition of oxide layer exactly because the oxides are arranged in the form of particles, and the surface is not flat causing inaccuracy of the microanalysis in the scanning electron microscope. The elemental analysis of cross section should be more accurate, though it has spatial resolution issues as well. The concentrations of the alloying elements in the steel are lower than those in the peeled-off area in the oxidation layer. The peeled-off area in the oxidation layer showed spinel. The concentrations of the alloying elements in the steel is lower than spinel because of the enrichment in spinel layer. Point 2 in Fig.3-(a) showed the composition of spinel layer in T91. Point 1 showed the composition of magnetite layer in T91. Point 5 in Fig.4-(c) showed the composition of T91 matrix. Stoichiometric ratio showed that the oxygen in spinel $\mathrm{Fe}\left(\mathrm{Fe}_{\mathrm{x}} \mathrm{Cr}_{1-\mathrm{x}}\right)_{2} \mathrm{O}_{4}$ was about $34.9 \%$ when $\mathrm{x}=0.7$.

The SIMP steel showed obvious corrosion character after contact with LBE. The surface morphology of oxidation layer is similar with the character of LBE corrosion layer on the Fe-Si alloy reported in literature [8]. LBE corrosion layer is compact with grain boundaries visible. In the reference it showed the same character of grain boundaries. It may be due to the high $\mathrm{Si}$ content in both alloys. There is no porous magnetite on the surfaces of the two steels under low oxygen condition. Elemental analysis showed that the $\mathrm{Cr}, \mathrm{Mn}, \mathrm{Si}$ and $\mathrm{O}$ are enriched in the oxide layer. However, the Fe is lower compared with the matrix.

The cross sections of the two steels after $500 \mathrm{~h}$ immersion in LBE are shown in Fig.6. After surface analyses on the oxide surface, the specimens were wrapped by epoxy resin, and ground for cross section analysis. The left section in Figs. 4 and 6 is matrix and right is epoxy resin. When sectioning, it was not possible to control to have Points 1, 2 or 3 in Fig. 3 to be exactly on the cross section. It can be found that the oxidation layers of the two steels are less than $10 \mu \mathrm{m}$ in thickness after contact with LBE for $500 \mathrm{~h}$. The oxide layer of SIMP is about $2.6 \mu \mathrm{m}$, and the carbide dissolution zone is about $3.9 \mu \mathrm{m}$. The oxide layer of T91 is about $7.1 \mu \mathrm{m}$, and the carbide dissolution zone is about $7.6 \mu \mathrm{m}$. The thickness of oxide layer was not uniform at different places. The above were average values. The oxide layers after $500 \mathrm{~h}$ corrosion were very thin in both steels. In optical microscopy, it is impossible to obtain high magnification pictures. The field 
emission-SEM (FE-SEM) provided higher magnification pictures, as presented in Fig.6-(c) and (d). After etching by Vilella's reagent, the cross section shows a white carbide dissolution layer beneath the oxidation layer, as shown in Fig.6-(b). The metal elements migrated away from the matrix in the vicinity of oxide layer during contact with LBE at high temperature. It is invisible under optical observation without etching. The oxidation layer and carbide dissolution layer of 1000 h's are thicker than 500 h's. In the carbide dissolution layer, the point analysis showed that the metal elements in the steel were gradually consumed, and carbides vanished, as shown in Tables 4 and 5 and Fig.6-(d). In the preliminary studies [7], the ferritization of austenitic stainless steels due to Ni preferential dissolution into LBE has been reported under the condition of high and middle oxygen concentrations above $823 \mathrm{~K}$ [9-13]. In fact the solubility of $\mathrm{Ni}, \mathrm{Cr}$ and $\mathrm{Fe}$ in the $\mathrm{LBE}$ at $673 \mathrm{~K}$ is about $1600 \mathrm{ppm}, 3.99 \mathrm{ppm}$ and smaller than $1 \mathrm{ppm}$, respectively, considerably supporting the experimental results [14]. The carbide dissolution layer could be found in the oxidation layer on SIMP because of the dissolution of metal elements in the steel, such as $\mathrm{Cr}$ and Fe, in LBE. The carbides in T91 are less than SIMP, as shown in Fig.1. So, the great decrease of carbides in the carbide dissolution layer was not observed in T91. However, carbides vanished greatly in the carbide dissolution layer of SIMP.

The oxidation layers on the two steels after $3000 \mathrm{~h}$ contact with LBE are present in Fig.4. It can be found that the oxidation layers grew compared with those after $500 \mathrm{~h}$ contact with LBE. The oxidation layer in SIMP is about $5 \mu \mathrm{m}$, and the carbide dissolution layer is about $10 \mu \mathrm{m}$. The oxidation layer in T91 is about $15 \mu \mathrm{m}$ and carbide dissolution layer is about $5 \mu \mathrm{m}$. The oxidation layer in SIMP is continuous and compact. There are many cavities in the oxidation layer on T91. Fazio et al. [12] considered that the T91 steel underwent metal element dissolution with the formation of cavities.

The oxidation layer under this condition was reduced greatly compared with the oxidation layer contacting with LBE with saturated oxygen for $1000 \mathrm{~h}$ and $2000 \mathrm{~h}$ [14]. High oxygen concentration in LBE is proved to be an accelerating key issue in the oxidation of structural materials. The oxide layer formed under oxygen saturated LBE was about $31.8 \mu \mathrm{m}$ after $500 \mathrm{~h}$ and $41.6 \mu \mathrm{m}$ after $1000 \mathrm{~h}$ in SIMP. The oxide layer in T91 was about $66.6 \mu \mathrm{m}$ after $500 \mathrm{~h}$ and 105.7 $\mu \mathrm{m}$ after $1000 \mathrm{~h}$.

When compared with the oxidation layer of $500 \mathrm{~h}$, it can be found that both the oxidation 
layer and carbide dissolution layer have grown after $3000 \mathrm{~h}$. For the scarcity of experimental data, it is impossible to obtain the growth curve of corrosion layer. However, it can be found that the oxidation layer and carbide dissolution layer grew greatly with the immersion time. The carbide dissolution layer indicated the leaching of metal elements in the steel during the corrosion.

Zhang [15] has observed the intergranular oxidation and oxide precipitates along grain boundaries below the $\mathrm{Fe}-\mathrm{Cr}$ spinel layer after corrosion by LBE at high temperature ( $823 \mathrm{~K}$ ). The results of these experiments are consistency with it. The internal oxidation zone of T91 was about $7.1 \mu \mathrm{m}$ after $3000 \mathrm{~h}$ in low oxygen LBE. The oxide layer in T91 was about $66.6 \mu \mathrm{m}$ after $500 \mathrm{~h}$ and $105.7 \mu \mathrm{m}$ after $1000 \mathrm{~h}$. The point analysis showed that the oxygen and the $\mathrm{Si}$ and $\mathrm{Cr}$ elements in the oxidation layer are high at grain boundaries, as shown in Fig.4-(c) and (e) and Table 4.

The chemical compositions of oxidation layer on T91 are shown in Table 4. Comparing data in Ref. [14] and Point 1 in Table 4, the Si content increased and Cr content decreased with time. No great variation was observed in Fe content. The oxide layer in Ref. [14] was formed in oxygen saturated LBE. The corrosion layer in the current paper was formed in low oxygen environment. It is hard to compare the oxygen content. The elemental analysis showed character of segregation and enrichment of metal elements. Oxides distributed along the grain boundary, as shown in Fig.4-(e). As presented in Fig.4-(e), the elemental analyses showed that the oxygen is high around grain boundaries. The point analyses showed higher oxygen in Point 3 compared with Point 2 . The thicker oxidation layer under oxygen saturated LBE showed intergranular oxidation in Ref. [14]. Compared with Point 2, it can be found that the oxygen and Cr, Mn and Si are higher at Point 3. Point 4 shows that the carbide dissolution zone has more oxygen than Point 5 in the matrix.

The chemical compositions of oxidation layer on SIMP are shown in Table 5. The outer oxidation layer was $\mathrm{Fe}-\mathrm{Pb}$ oxide. The enrichment of $\mathrm{Cr}$ and $\mathrm{Si}$ was found in the inner oxidation layer. Point 3 shows the composition of carbide dissolution layer. Compared with Point 4 in the matrix, there is higher oxygen concentration and lower $\mathrm{Cr}$ in the carbide dissolution layer.

\subsection{Discussion}

The experimental results showed that the corrosion layer on SIMP is thinner than that on T91 after contact with LBE for the same time. The reason is that SIMP has better corrosion resistance in LBE than T91 due to the differences in microstructure and composition of the two steels. The PBR (Pilling-Bedworth ratio) of $\mathrm{Cr}$ and $\mathrm{Si}$ are 2.07 and 2.26, respectively [16]. The chromium 
hemitrioxide and silicon dioxide have excellent anti-oxidation ability. In the previous study it was reported that the continuous and compact oxidation layer could be formed on the surface of the steel only when the $\mathrm{Cr}$ content was over $15 \mathrm{wt} \%[17,18])$. The oxidation layers of the two steels cannot stop the corrosion from LBE. The dissolution limit of Ni in LBE is high, which is increased as temperature rises, resulting in serious attack of dissolution corrosion [5, 19]. The more $\mathrm{Si}$ and $\mathrm{Cr}$ contents, and absent Ni content help SIMP to possess higher resistance to LBE corrosion than T91.

Grain boundaries are short-cut channels for oxygen to migrate inward and the elements in steels to diffuse outward. The grain size of SIMP was larger, about 2 times of T91. The larger grain size reduced the amount of grain boundaries. Therefore the number of channels for oxygen to migrate inward and the element dissolution were reduced. More experiments are needed to obtain more acute conclusions.

\section{Conclusion}

A comparative study on the compatibility to liquid lead-bismuth eutectic of T91 and SIMP steels was carried out. After contact with LBE in sealed quartz glass tube for $500 \mathrm{~h}$ and $3000 \mathrm{~h}$, cross section observation showed that both steels showed alloying elements enrichment in the corrosion layer, and the carbide dissolution layer formed between oxidation layer and the steel matrix. The oxidation layer on SIMP was thinner than T91. Differences in microstructure and chemical composition made SIMP possess better oxidation resistance than T91, which makes it a good candidate structural material for ADS system.

\section{Acknowledgments}

This work was financially supported by a subtopic (XDA03010301, XDA03010302) of Advanced Fission Energy Program-ADS Transmutation System, Chinese Academy of Sciences Strategic Priority Research Program (XDA03010000).

\section{References}

[1] N. Li, J. Nucl. Mater., 300 (2002) 73-81.

[2] M. Takahashi, M. Kondo, K. Miura, T. Onizawa, J. Nucl. Mater., 357 (2006) 97-104.

[3] A. Weisenburger, K. Aoto, G. Müller, A. Heinzel, G. Schumacher, T. Furukawa, J. Nucl. Mater., 358 (2006) 69-76.

[4] J. Van den Bosch, G. Coen, W. Van Renterghem, A. Almazouzi, J. Nucl. Mater., 396 (2010) 57-64.

[5] F. Barbier, G. Benamati, C. Fazio, A. Rusanov, J. Nucl. Mater., 295 (2001) 149-156.

[6] L. Martinelli, C. Jean-Louis, B.-C. Fanny, Nucl. Eng. Des., 241 (2011) 1288-1294. 
[7] Y. Kurata, M. Futakawa, S. Saito, J. Nucl. Mater., 373 (2008) 164-178.

[8] A.L. Johnson, E.P. Loewen, T.T. Ho, D. Koury, B. Hosterman, U. Younas, J. Welch, J.W. Farley, J. Nucl. Mater., 350 (2006) 221-231.

[9] G. Benamati, C. Fazio, H. Piankova, A. Rusanov, J. Nucl. Mater., 301 (2002) 23-27.

[10] Y. Kurata, M. Futakawa, J. Nucl. Mater., 325 (2004) 217-222.

[11] Y. Kurata, M. Futakawa, S. Saito, J. Nucl. Mater., 343 (2005) 333-340.

[12] C. Fazio, I. Ricapito, G. Scaddozzo, G. Benamati, J. Nucl. Mater., 318 (2003) 325-332.

[13] G. Müller, A. Heinzel, J. Konys, G. Schumacher, A. Weisenburger, F. Zimmermann, V. Engelko, A. Rusanov, V. Markov, J. Nucl. Mater., 301 (2002) 40-46.

[14] Q. Shi, J. Liu, H. Luan, Z. Yang, W. Wang, W. Yan, Y. Shan, K. Yang, J. Nucl. Mater., 457 (2015) 135-141.

[15] J. Zhang, Oxid. Met., 80 (2013) 669-685.

[16] T. Ohashi, T. Harada, Oxid. Met., 46 (1996) 235-254.

[17] J. Lim, I.S. Hwang, J.H. Kim, J. Nucl. Mater., 441 (2013) 650-660.

[18] J. Robertson, Corros. Sci., 32 (1991) 443-465.

[19] J. Zhang, N. Li, J. Nucl. Mater., 373 (2008) 351-377. 
Table 1 Chemical compositions of steels in LBE corrosion experiment ( $\mathrm{wt} \%)$

\begin{tabular}{lllllllllll}
\hline Steel & $\mathrm{C}$ & $\mathrm{Si}$ & $\mathrm{V}$ & $\mathrm{Cr}$ & $\mathrm{Mn}$ & $\mathrm{Ni}$ & $\mathrm{W}$ & $\mathrm{Mo}$ & $\mathrm{Nb}$ & $\mathrm{Ta}$ \\
\hline T91 & 0.10 & 0.26 & 0.2 & 8.45 & 0.46 & 0.17 & - & 0.92 & 0.04 & - \\
SIMP & 0.25 & 1.5 & 0.2 & 10.8 & 0.5 & - & 1.2 & 0.9 & 0.01 & 0.11 \\
\hline
\end{tabular}

Table 2 Analyses of the local energy spectrum in Fig.3 (wt\%)

\begin{tabular}{llllllll}
\hline Location & $\mathrm{O}$ & $\mathrm{Si}$ & $\mathrm{V}$ & $\mathrm{Cr}$ & $\mathrm{Fe}$ & $\mathrm{Mn}$ & $\mathrm{W}$ \\
\hline Point 1 (T91, magnetite) & 14.0 & 0.7 & 0.5 & 21.9 & 58.5 & 0.7 & - \\
Point 2 (T91, spinel) & 20.1 & 1.3 & 0.7 & 31.6 & 36.7 & 1.4 & - \\
Point 3 (T91, spinel) & 12.6 & 5.5 & 0.7 & 28.0 & 48.8 & 1.7 & 2.7 \\
\hline
\end{tabular}

Table 3 Analyses of the local energy spectrum in Fig.5 (wt\%)

\begin{tabular}{lrllllllll}
\hline Location & $\mathrm{O}$ & $\mathrm{Si}$ & $\mathrm{V}$ & $\mathrm{Cr}$ & $\mathrm{Fe}$ & $\mathrm{Mn}$ & $\mathrm{Ni}$ & $\mathrm{Pb}$ & $\mathrm{Bi}$ \\
\hline Spectrum 146 (T91, oxide) & 0.6 & 0.3 & 0.5 & 14.7 & 26.4 & 0.6 & 0.2 & 26.7 & 30.0 \\
Spectrum 160 (SIMP, oxide) & 15.8 & 1.2 & - & 8.9 & 18.3 & - & - & 31.4 & 24.4 \\
\hline
\end{tabular}

Table 4 Analysis of local energy spectrum of T91 in Fig.4-(c) (wt\%)

\begin{tabular}{lrrrrrr}
\hline Location & $\mathrm{O}$ & $\mathrm{Si}$ & $\mathrm{Cr}$ & $\mathrm{Fe}$ & $\mathrm{Mn}$ & $\mathrm{Ni}$ \\
\hline Point 1 (oxidation) & 19.3 & 1.1 & 14.0 & 64.7 & - & - \\
Point 2 (internal oxidation: grain) & 6.0 & 0.4 & 5.5 & 87.7 & 0.1 & 0.4 \\
Point 3 (internal oxidation: grain boundary) & 34.4 & 1.5 & 36.0 & 27.3 & 0.4 & 0.1 \\
Point 4 (carbide dissolution zone) & 9.1 & 0.2 & 2.2 & 87.7 & 0.1 & 0.5 \\
Point 5 (matrix) & 0.1 & 0.3 & 3.3 & 95.6 & - & - \\
\hline
\end{tabular}

Table 5 Analysis of local energy spectrum of SIMP in Fig.4-(d) (wt\%)

\begin{tabular}{lrrrrrc}
\hline Location & $\mathrm{O}$ & $\mathrm{Si}$ & $\mathrm{Cr}$ & $\mathrm{Fe}$ & $\mathrm{Mn}$ & $\mathrm{Pb}$ \\
\hline Point 1 (oxidation) & 4.7 & 1.2 & 6.5 & 86.7 & 0.8 & 0.2 \\
Point 2 (internal oxidation) & 22.9 & 2.7 & 26.5 & 46.9 & 0.8 & - \\
Point 3 (carbide dissolution zone) & 7.0 & 1.3 & 6.3 & 85.2 & 0.3 & - \\
Point 4 (matrix) & - & 1.1 & 13.1 & 83.1 & - & - \\
\hline
\end{tabular}




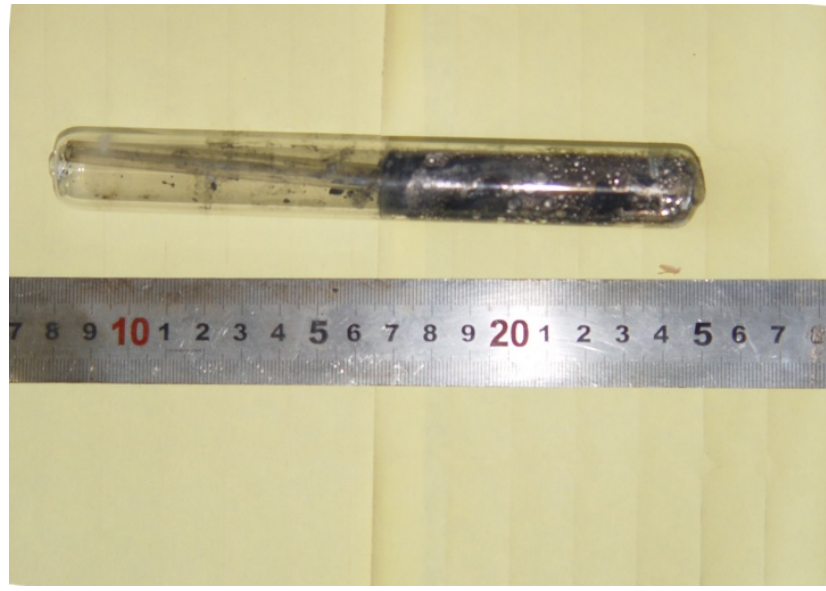

Fig. 1 The quartz glass tube before heating at $873 \mathrm{~K}$
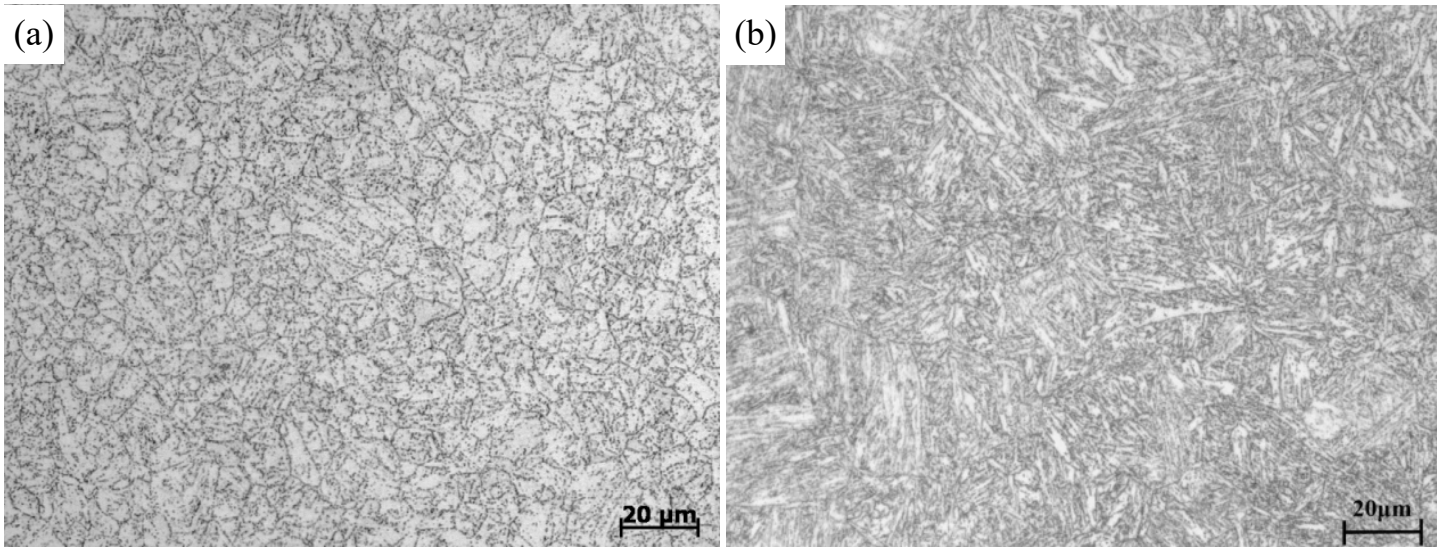

Fig.2 Microstructures of T91 and SIMP steels. (a) T91, OM; (b) SIMP, OM 

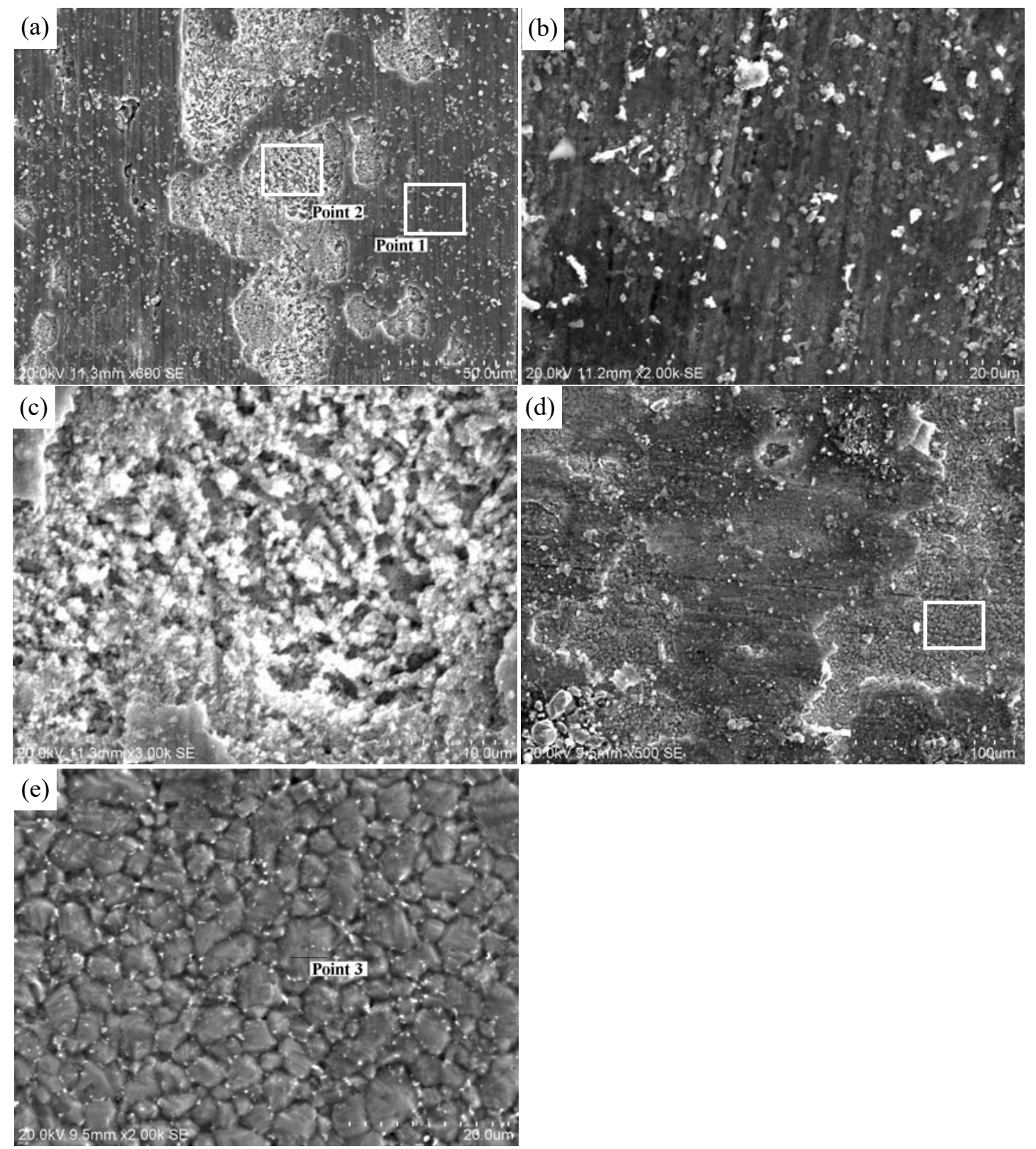

Fig. 3 SEM observations of the sample surfaces after contact with LBE at $873 \mathrm{~K}$ for $3000 \mathrm{~h}$. (b), (c) and (e) are enlarged views of the marked areas in (a) (d). (a); (b); (c) T91-3000 h; (d); (e) SIMP-3000 h 

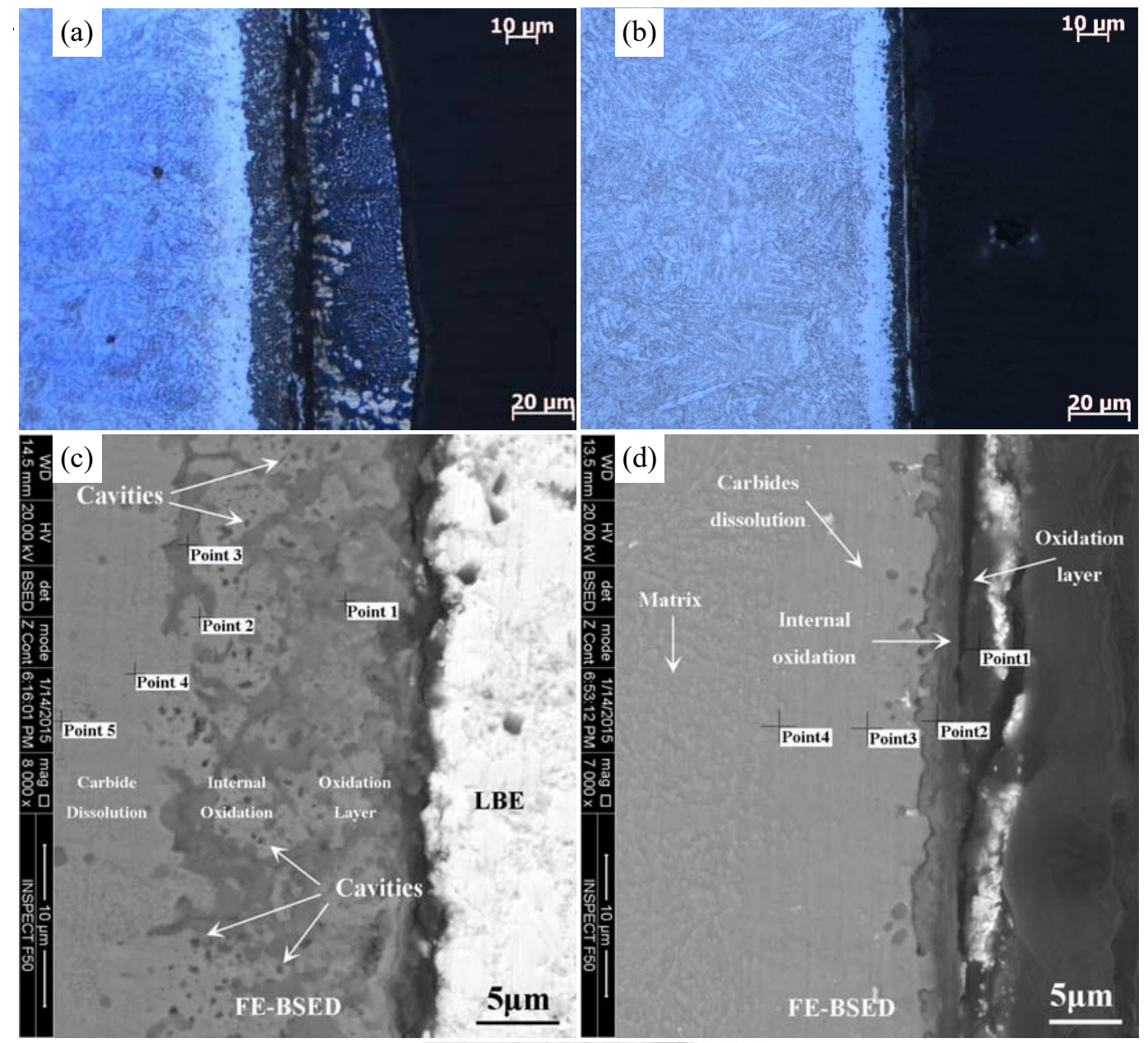

20 II
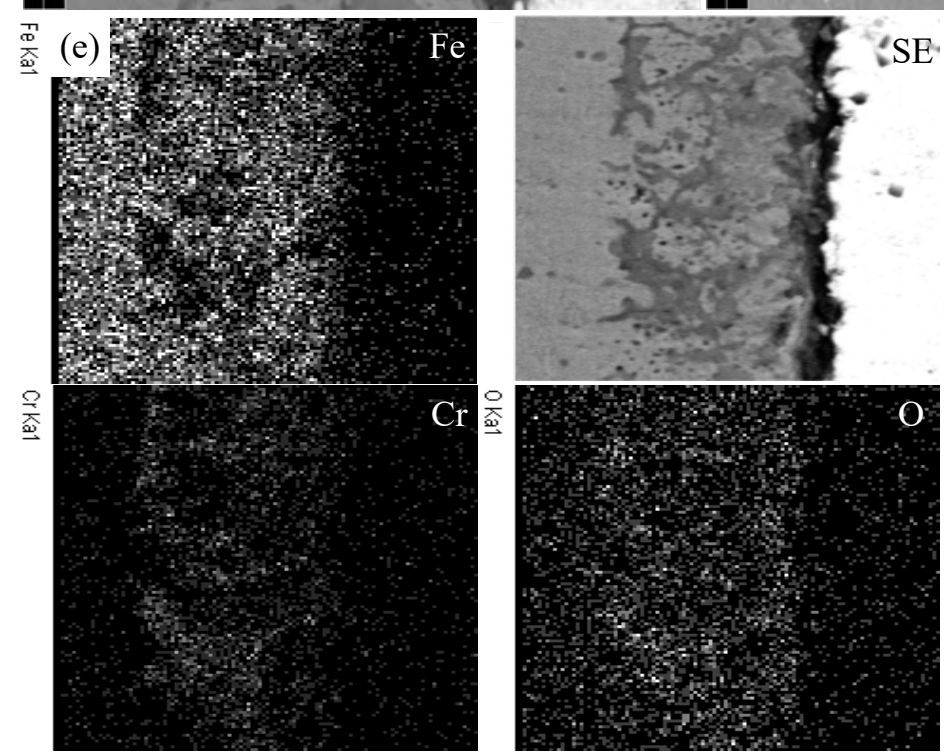

FE-BSELD

$5 \mu \mathrm{m}$

올

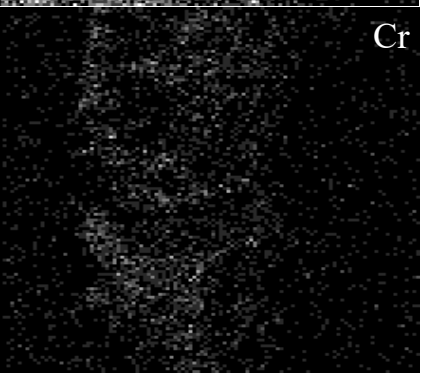

Fig.4 Oxidation layers of cross sections of two steels after contact with LBE at $873 \mathrm{~K}$ for $3000 \mathrm{~h}$. (a) T91-OM; (b) SIMP-OM; (c) T91-FE-SEM where the white zone is LBE; (d) SIMP-FE-SEM; (e) elements map of T91 


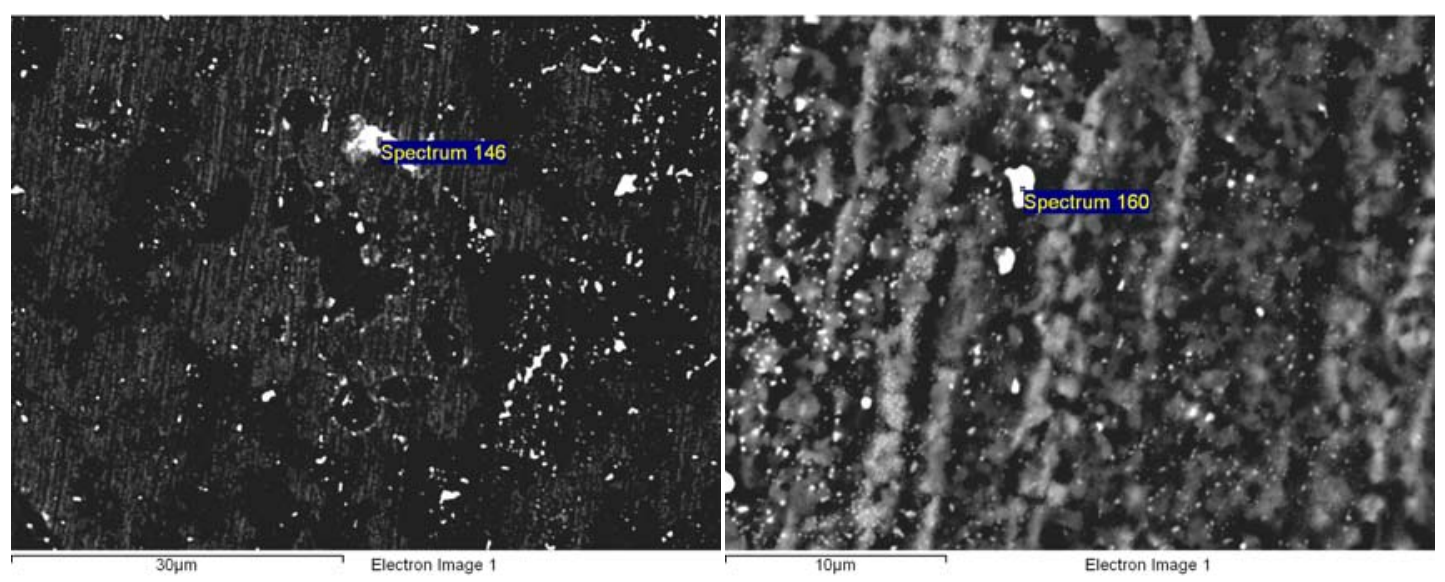

(a)

(b)

Fig.5 Surface of (a) T91 and (b) SIMP

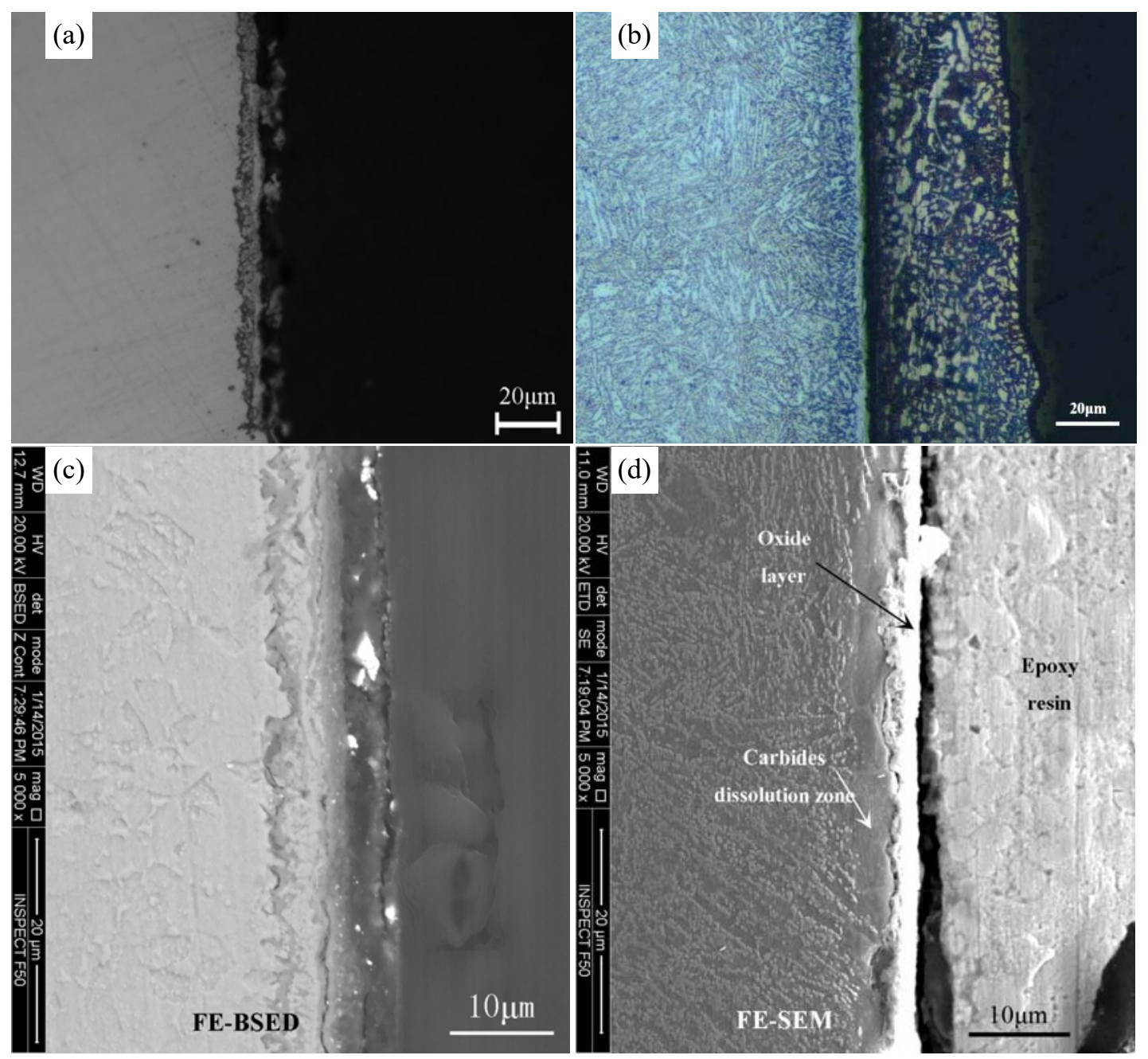

Fig.6 Oxidation layers of cross sections of two steels after contact with LBE at $873 \mathrm{~K}$ for $500 \mathrm{~h}$. (a) T91-OM; (b) SIMP-OM; (c) T91-FE-SEM; (d) SIMP-FE-SEM where the white zone is not LBE 